This document is the Accepted Manuscript version of a Published Work that appeared in final form in Energy Environ. Sci., 2015, 8, 2010 DOI: 10.1039/c5ee00444f

\title{
Metal-free organic sensitizers with narrow absorption in the visible for solar cells exceeding $10 \%$ efficiency
}

\author{
D. Joly; L. Pelleja; S. Narbey; F. Oswald; T. Meyer; Y. Kervella; P. Maldivi; \\ J. N. Clifford; E. Palomares; R. Demadrille
}

\begin{abstract}
A novel family of six donor-acceptor type organic sensitizers for dye-sensitized solar cells (DSSCs) is reported. The dyes have been designed to have outstanding light absorption properties in the visible range and being able to achieve high photon-to-electrical current conversion for BIPV (building-integrated photovoltaic). Moreover, stability tests under illumination at 1 Sun and $651 \mathrm{C}$ showed a great stability for some of the devices, with less than $6 \%$ decrease of power conversion efficiency after 3000 hours. The differences in the performance of the six sensitizers under standard illumination conditions can be correlated with the observed differences in the photo-induced transient photovoltage and in charge extraction measurements. We report the use of one of the dyes for the fabrication of semi-transparent solar modules showing an active area of $1400 \mathrm{~cm}^{2}$ and a power output of $10.5 \mathrm{~W} \mathrm{~m}^{-2}$.
\end{abstract}

\begin{abstract}
Broader context
Tremendous progress has been achieved in the past decade in the effciency of dye-sensitized mesoscopic solar cells (DSSC), owing to the development of new metal-free organic sensitizers. To increase their commercial attractiveness and to make them a realistic approach towards energy markets such as BIPV (building integrated photovoltaics), the new dyes must be cheap, colorful, and effcient, and moreover they must show a high stability. In this paper, we report a family of donor-acceptor type metal-free photosensitizers with simple structures for DSSCs. The precise molecular design of the dyes leads to a quite narrow light absorption in the visible range and a high photon-to-electrical current conversion in solar cells. These organic sensitizers that can be prepared in few steps show power efficiencies over $10 \%$ when they are used with iodine-based liquid electrolytes. Stability tests and fabrication of semitransparent solar modules

with an active area of $1400 \mathrm{~cm}^{2}$ demonstrate the potential of these organic dyes for large scale applications and mass production for BIPV.
\end{abstract}

\section{Introduction}

Among the novel emerging photovoltaic technologies suitable for BIPV, dye-sensitized solar cells (DSSCs) have the potential of becoming a clean and affordable source of renewable energy. Their high performance combined with low-cost manufacturing processes and steadily improved stability has drawn tremendous

${ }^{\text {a }}$ Univ. Grenoble Alpes, INAC-SPRAM, F-38000 Grenoble, France

${ }^{\mathrm{b}}$ CNRS, Alpes, INAC-SPRAM, F-38000 Grenoble, France

${ }^{\mathrm{c}}$ CEA, INAC-SPRAM, F-38000 Grenoble, France. E-mail: renaud.demadrille@cea.fr

d 17 Rue des Martyrs, 38054 Grenoble Cedex 9, France

${ }^{\mathrm{e}}$ Institute of Chemical Research of Catalonia (ICIQ), Avenguda Països Catalans, 16, Tarragona 43007, Spain. E-mail: epalomares@iciq.es

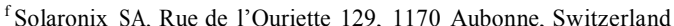

${ }^{g}$ Univ. Grenoble Alpes, CEA, INAC-SCIB, F-38000 Grenoble, France

${ }^{\text {h }}$ ICREA, Passeig Lluís Companys, 23, Barcelona, E-08010, Spain interest from both academic and industrial researchers. In these devices, photons are absorbed by photoactive molecules that are anchored to the surface of a mesoporous wide band gap semi- conductor oxide such as $\mathrm{TiO}_{2},{ }^{1 \mathrm{a}-\mathrm{c}} \mathrm{ZnO}$, ${ }^{1 \mathrm{~d}}$ or $\mathrm{Zn}_{2} \mathrm{SnO}_{4}$, ${ }^{\text {le, } \mathrm{f}}$ which is deposited on a transparent conductive oxide. ${ }^{1}$ The system is

usually completed with a liquid electrolyte containing a redox shuttle. In a DSSC, the sensitizer is a crucial element, because it is responsible for the absorption of photons and the generation of free charges after the injection of electrons from the excited state of the dye into the semi-conducting oxide. Furthermore the dye acts as the first "barrier" for back-electron transfer from the photo-injected electrons to the oxidised electrolyte.

Presently, the dyes for DSSCs can be classified into three main categories: (i) ruthenium-containing dyes such as polypyridyl complexes, (ii) metallated porphyrins and (iii) fully organic dyes whose structure is based on a typical "electron donor-p-bridge- electron acceptor" (D-p-A) design. ${ }^{2}$

Ruthenium-dye based DSSCs can show high effciency (10-11\%) due to their wide absorption spectra ranging from the visible to 
the near-infrared (NIR), but on the other hand, the use of toxic and scarce ruthenium inhibits their application for mass production.

Ring-metalated porphyrin dyes were used for the first time

as sensitizers in DSSCs in 2007. ${ }^{3}$ Taking advantage of their large absorption coefficients in the visible region associated with their Soret and Qbands, impressive progress has been made with this class of materials leading to power conversion efficiencies (PCEs) up to $12-13 \%$ when a cobalt-based electrolyte is employed. ${ }^{4}$ However, the multiple steps that are necessary for their preparation, the low yield of porphyrin formation and the

inherent difficulties in their purification indicate that they will not be suitable candidates for use in DSSC technology in the near future. On the other hand, fully organic sensitizers present many advantages as they can be prepared in a few steps, they can be purified using simple methods, and thanks to molecular engineering one can conveniently tune their energy band gap to

modulate their light-harvesting capabilities. ${ }^{5 \mathrm{a}, \mathrm{b}}$

To date, when combined with the classical iodide/tri-iodide

$\left(\mathrm{I}^{-} / \mathrm{I}_{3}{ }^{-}\right)$electrolyte, only a few metal-free organic sensitizers are capable of achieving over $9 \%$ photovoltaic effciency. ${ }^{5 \mathrm{c}-\mathrm{f}}$ The iodide/triiodide redox shuttle $\left(\mathrm{I}^{-} / \mathrm{I}_{3}{ }^{-}\right)$is the most widely used system, because it has favorable penetration ability into the pores of the semiconductor oxide film, and it gives rise to a very fast dye regeneration and relatively slow recombination with injected photoelectrons. ${ }^{6}$ The main drawback is the fact that the redox potential of $\left(\mathrm{I}^{-} / \mathrm{I}_{3}{ }^{-}\right)$couple limits the photovoltage. However this system is until now the only redox couple which has been proven to have long term stability. ${ }^{7}$

For the development of devices applicable in BIPV such as skylights or façades, it now appears crucial to develop new efficient and robust sensitizers with selected absorption in the visible.

In this paper we report a new family of D-p-A organic dyes revealing a narrow absorption in the visible that can be combined with $\left(\mathrm{I}^{-} / \mathrm{I}_{3}^{-}\right)$based electrolytes for the development of highly efficient and stable semi-transparent solar cells. These dyes are based on the molecular structure of RK1, a robust organic dye that achieved $10.20 \%$ efficiency. ${ }^{5 \mathrm{~d}}$ The performance is comparable with that of conventional N719, which gave identical efficiency under the same experimental conditions.

Five different dyes were prepared and fully characterized by electrochemical and spectroscopy techniques. The photovoltaic performances of these sensitizers in DSSC devices were inves- tigated under standard A.M 1.5G simulated solar radiation. After optimization of the electrode thickness and dyeing conditions, and using a volatile electrolyte, all the dyes showed power con- version effciencies over $8.50 \%$ and four of them had efficiencies ranging from $9.51 \%$ to $10.11 \%$ with current $\operatorname{densities}\left(\mathrm{J}_{\mathrm{sc}}\right)$

spanning from $16.55 \mathrm{~mA} \mathrm{~cm}^{-2}$ to $18.82 \mathrm{~mA} \mathrm{~cm}^{-2}$.

When the volatile electrolyte was replaced by an ionic liquid based one, effciencies up to $7.87 \%$ with $\mathrm{J}_{\mathrm{sc}}$ up to $17.50 \mathrm{~mA} \mathrm{~cm} \mathrm{~cm}^{-2}$ were obtained. These values are among the highest reported for organic sensitizers with a nonvolatile electrolyte. Herein, we discuss the difference in DSSC performances utilizing these dyes by monitoring the electron transfer processes in complete devices,

and using a full set of electrochemical and optical data combined with theoretical modelling.

\section{Results and discussion}

\subsection{Design and synthesis of the RK sensitizers}

The chemical design of the sensitizers was inspired by the molecular structure of RK1, an effcient orange dye that can be obtained in only five steps with an overall yield of $50 \%$. One should note that the development of convenient and up-scalable synthetic methods is important for future development of DSSCs at the industrial level. With the goal to tune the absorption spectrum of RK1 and to improve its solubility in various nonhalogenated solvents, several strategies were followed in this work (Fig. 1).

First, alkoxy groups or alkyl substituents were introduced in the para position of the triphenylamine (TPA) unit leading respectively to dyes 6ORK1 and 6RK1.

In addition, to confer better solubility, the introduction of long alkyl and alkoxy groups on the electron-donating moiety is expected to produce a red-shift in the absorption spectra $^{8}$ and to diminish dye aggregation and charge recombination, ${ }^{9}$ leading to an increase in the $\mathrm{J}_{\mathrm{sc}}$ value. $^{10}$ Therefore, the linear octyl substituent of the thiophene unit in RK1 was replaced by a branched alkyl chain, i.e. 2-ethylhexyl, leading to dye RK2. The presence of the branched 2-ethylhexyl chain is expected to suppress the charge recombination between electrons in the

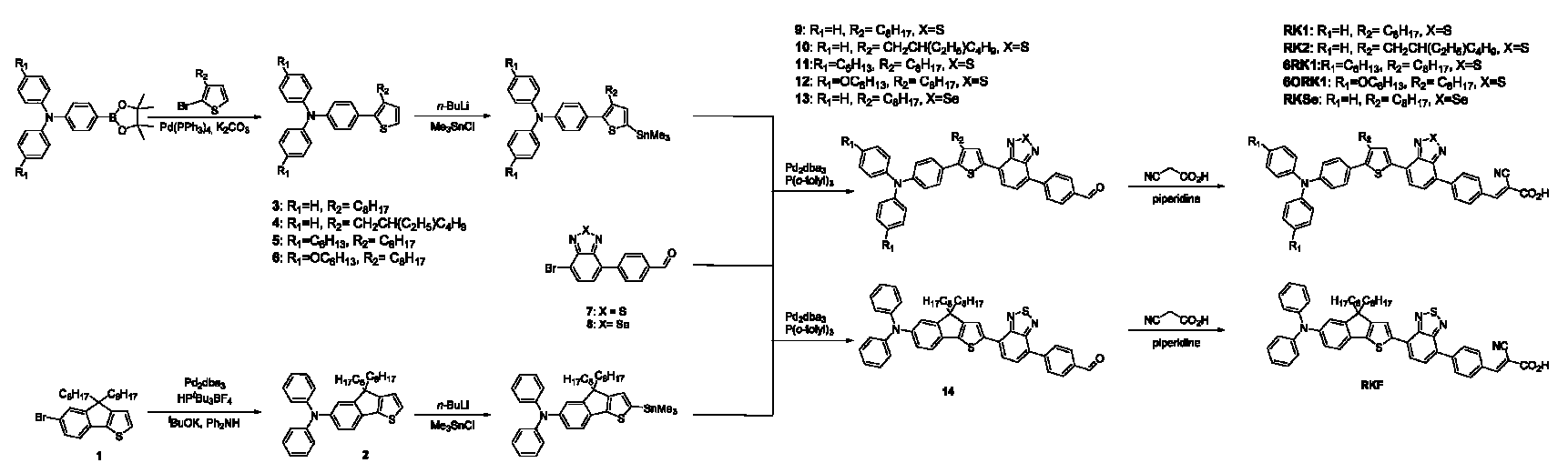

Fig. 1 Synthetic routes and chemical structures of the organic sensitizers. 
electrolyte and the $\mathrm{TiO}_{2}$ film more efficiently than the linear octyl chain. $^{11}$

In order to shift the position of the internal charge transfer absorption band (ICT) in the visible range towards higher wavelengths and, as a consequence to tune the color of the dyes, two approaches have been investigated. First, the sulfur atom of the benzothiadiazole electron-accepting unit was replaced by a selenium atom ${ }^{12}$ giving rise to the dye RKSe. Second, the

rigidification of the backbone was carried out with the goal of improving the delocalization of the p-electrons over the TPA and the p-conjugated bridge. ${ }^{13}$ This was achieved by fusing the phenyl ring of the TPA with the thiophene unit of the central unit leading to the dye RKF. The substitution of the resulting indeno[1,2-b]- thiophene moiety with two octyl chains will ensure good solubility for this dye.

The synthetic strategies developed to access the different dyes are illustrated in Fig. 1. These involve various palladium- catalyzed crosscoupling reactions. Suzuki coupling was employed to prepare the TPA(alkyl)thiophene building blocks 3, 4, 5, and

6 whereas a Buchwald-Hartwig coupling reaction was used to prepare compound 2, namely TPA-(4,4-dioctyl-4H-indeno[1,2-b]- thiophene). Finally a Stille coupling reaction was chosen to access the six different aldehyde intermediates starting from the stannyl- ated TPA-based precursors and the brominated benzothiadiazole or benzoselenadiazole benzaldehyde reagents 7 and 8 respectively.

All the compounds bearing an aldehyde functional group, i.e. 9, 10, $11,12,13$, and 14 , were subsequently converted into the corresponding dyes by Knoevenagel condensation with cyano- acrylic acid in the presence of piperidine. RK2, 6ORK1, 6RK1, RKSe and RKF were obtained with average to good overall yields ranging from $11 \%$ to $41 \%$. All the intermediates and the sensiti- zers were fully characterized; the synthetic procedures and analytical data are reported in the ESI. $\dagger$

\subsection{Optical and electrochemical data and DFT calculations}

The UV-vis absorption spectra of the five new dyes in $\mathrm{CH}_{2} \mathrm{Cl}_{2}$ solution and on $2 \mathrm{~mm}$ thick $\mathrm{TiO}_{2}$ films are shown in Fig. 2 and compared to that of RK1 which is our reference dye. The absorp- tion bands as well as their extinction coefficients are summarized in Table 1.

As expected for the commonly used D-p-A structure, two sets of absorption bands are observed. The first one is attri- buted to the $\mathrm{p}-\mathrm{p}^{*}$ transitions of the aromatic rings being in conjugation and is located in the UV region with an extension close to the frontier between the UV and the visible regions.

The second one is associated with the intramolecular charge transfer (ICT) absorption and is clearly located in the visible region. The replacement of the linear alkyl chain on the thio- phene unit by a branched one (RK2) has absolutely no influence on the position and the width of the UV absorption band. The introduction of alkoxy or alkyl groups on the TPA unit in the para position (6ORK1 and 6RK1) as well as by a Se atom (RKSe) induces a slight bathochromic shift of the UV band of circa $15 \mathrm{~nm}$ in solution. The effect of the bridged unit resulting from the fusion between the TPA and the thiophene unit in RKF is more pronounced. In this case two absorption bands are observed
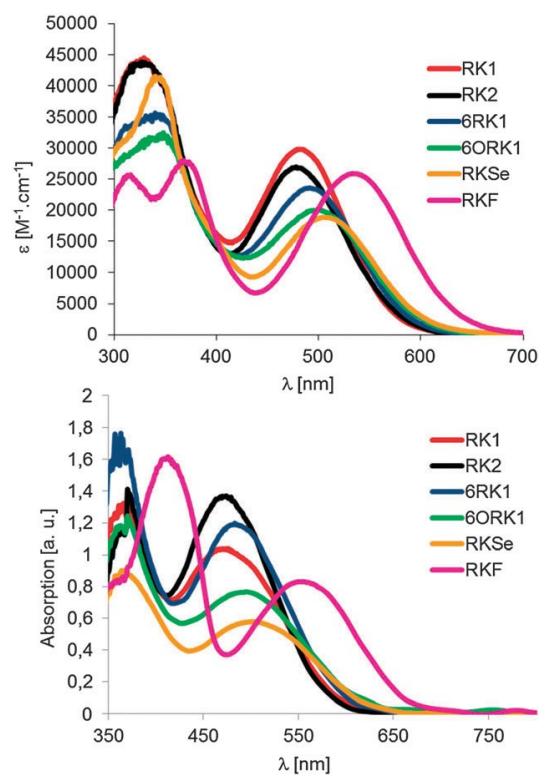

Fig. 2 Absorption spectra of RK dyes in $\mathrm{CH}_{2} \mathrm{Cl}_{2}$ (top), on $\mathrm{TiO}_{2}$ films (bottom).

in the UV and the $\mathbf{1}_{\max }$ of the UV band is bathochromically shifted by $38 \mathrm{~nm}$ compared to RK1.

As mentioned before, all of the synthesized dyes have absorption maxima in the visible region (between 475 and

$535 \mathrm{~nm}$ ) originating from an intramolecular charge transfer.

The intensity and the position of the ICT bands are strongly dependent on the modification of the chemical structure. The replacement of the octyl group in RK1 by a 2-ethylhexyl group in RK2 results in a slight hypsochromic and hypochromic effect on the ICT band. This may be explained by the steric hindrance induced by the branched chain that increases the torsion angle between the TPA and the thiophene unit.

This torsion impedes good delocalization of the $\mathrm{p}$ electrons and blue-shifts the position of the ICT band. On the other hand, the introduction of alkyl and alkoxy donating units on the TPA moiety induces a red-shift of $6 \mathrm{~nm}$ and $14 \mathrm{~nm}$ respec- tively for 6RK1 and 6ORK1 leading to more reddish dyes. This shift is associated to a decrease of the molar extinction coefficient attributed to the increased proportion of the alkyl chains. A more pronounced bathochromic effect is observed when the benzothiadiazole electron withdrawing unit is replaced by a benzoselenadiazole unit in RKSe. This shift is attributed to the higher electron accepting ability of the benzoselenadiazole unit as confirmed by the better localization of the LUMO energy level on this unit (see DFT calculations, ESI, $\uparrow$ Fig. S3). Herein the decrease of the molar absorption coefficient is more important which could be understood by the low oscillator strength of the charge-transfer transition according to the Franck-Condon principle. $^{9 \mathrm{~b}}$

The most important bathochromic effect of the ICT band is observed for RKF yielding a pink-violet dye. The indeno- thiophene bridged unit plays a critical role in the enhanced absorption of RKF. Indeed, the planarization of the TPA with the adjacent thiophene leads to an increased delocalization of 
Table 1 Optical and electrochemical data of the RK dyes

\begin{tabular}{|c|c|c|c|c|c|c|c|c|c|c|c|}
\hline & $\begin{array}{l}\mathbf{1}_{\max } \\
\mathrm{UV}^{\mathrm{a}}[\mathrm{nm}]\end{array}$ & $\begin{array}{l}\mathbf{1}_{\max } \\
\operatorname{Vis}^{\mathbf{a}}[\mathrm{nm}]\end{array}$ & $\mathbf{1}_{\mathrm{em}}^{\mathrm{a}}[\mathrm{nm}]$ & $\begin{array}{l}\mathrm{e}^{\mathrm{a}} \\
{\left[\mathrm{M}^{-1} \mathrm{~cm}^{-1}\right]}\end{array}$ & $\mathrm{DE}_{\mathrm{opt}}^{\mathrm{b}}[\mathrm{eV}]$ & $\begin{array}{l}\mathrm{E}\left(\mathrm{S}^{+} / \mathrm{S}\right)^{\mathrm{c}} \\
{[\mathrm{eV}]}\end{array}$ & $\begin{array}{l}\mathrm{E}(0-0)^{\mathrm{d}} \\
{[\mathrm{eV}]}\end{array}$ & $\mathrm{E}\left(\mathrm{S}^{+} / \mathrm{S}^{*}\right)^{\mathrm{e}}[\mathrm{V}]$ & $\begin{array}{l}\text { LUMO }^{\mathrm{f}} \\
{[\mathrm{eV}]}\end{array}$ & $\begin{array}{l}\mathrm{HOMO}^{\mathrm{f}} \\
{[\mathrm{eV}]}\end{array}$ & $\mathrm{DE}^{\mathrm{g}}[\mathrm{eV}]$ \\
\hline RK1 & $330(364)$ & $484(471)$ & 713 & 27600 & 2.12 & -5.62 & 2.15 & -3.47 & -3.22 & -5.23 & 2.01 \\
\hline RK2 & $330(371)$ & 477 (472) & 720 & 26900 & 2.16 & -5.65 & 2.06 & -3.6 & -3.21 & -5.23 & 2.02 \\
\hline 6RK1 & $344(363)$ & $490(484)$ & 732 & 23000 & 2.09 & -5.53 & 2.10 & -3.44 & -3.22 & -5.12 & 1.90 \\
\hline 6ORK1 & $345(364)$ & $498(495)$ & 578 & 19900 & 2.00 & -5.39 & 2.30 & -3.08 & -3.21 & -5.03 & 1.82 \\
\hline RKSe & 343 (364) & $510(505)$ & 745 & 18200 & 2.00 & -5.64 & 1.97 & -3.67 & -3.42 & -5.23 & 1.81 \\
\hline RKF & 368 (412) & $533(553)$ & 733 & 25900 & 1.87 & -5.45 & 2.04 & -3.41 & -3.21 & -5.14 & 1.93 \\
\hline
\end{tabular}

${ }^{\text {a }}$ Measured in $\mathrm{CH}_{2} \mathrm{Cl}_{2}$, in parentheses measured onTiO $2(2 \mathrm{~mm})$. ${ }^{\mathrm{b}}$ Measured on $\mathrm{TiO}_{2}(2 \mathrm{~mm})$ from $\mathbf{1}_{\text {onset. }}{ }^{\mathrm{c}}$ All potentials were obtained during cyclic voltammetric investigations in $0.2 \mathrm{M} \mathrm{Bu}_{4} \mathrm{NPF}_{6}$ in $\mathrm{CH}_{2} \mathrm{Cl}_{2}$. Platinum electrode diameter $1 \mathrm{~mm}$, sweep rate $200 \mathrm{mV} \mathrm{s}^{-1}$. Potentials measured vs. Fc $/$ Fc were converted to NHE by addition of $+0.69 \mathrm{~V} .{ }^{\mathrm{d}}$ The zero-zero excitation energies, $\mathrm{E}(0-0)$, are estimated from the intercept of the normalized absorption and emission spectra. ${ }^{\mathrm{e}}$ The excited state oxidation potentials were derived from the equation $\mathrm{E}\left(\mathrm{S}^{+} / \mathrm{S}^{*}\right)=\mathrm{E}\left(\mathrm{S}^{+} / \mathrm{S}\right)-\mathrm{E}(0-0) .{ }^{\mathrm{f}}$ Calculation B3LYP. ${ }^{\mathrm{g}} \mathrm{DE}=$ HOMO-LUMO from calculation.

the HOMO energy level as revealed by DFT calculations. The higher electron-donating ability of this unit and the better delocalization of electrons shift by ca. $50 \mathrm{~nm}$ the position of the ICT band.

When the dyes are absorbed on the $\mathrm{TiO}_{2}$ surface, they undergo a red shift of their UV absorption band and a slight hypsochromic shift of the visible absorption band is observed for all the dyes (from 4 to $13 \mathrm{~nm}$ ) except for RKF. With this dye we observed a red-shift of the visible absorption band. This may indicate that the dyes have the propensity to form $\mathrm{H}$-aggregates onto the $\mathrm{TiO}_{2}$ surface whereas $\mathrm{RKF}$ tends to form Jaggregates owing to the two alkyl substituents attached to the spiro-carbon.

The electrochemical properties of the dyes were investigated by cyclic voltammetry $(\mathrm{CV})$ in dichloromethane with the goal to determine the energy level positions of their frontier orbitals. Upon application of positive potentials they showed two reversible oxidation waves corresponding to an oxidation/re-reduction pro- cess (see ESI, $\dagger$ Fig. S1). Upon application of negative potentials, the dye undergoes a quasi-reversible reduction/re-oxidation process. As shown in Table 1, the LUMO energy levels that are determined from the onset of the reduction waves are lying between -3.57 and

$-3.78 \mathrm{eV}$ for all the sensitizers. The lowest LUMO value was

found for the selenium-containing dye, reflecting the increased electronwithdrawing character of the benzoselenadiazole unit. All the LUMO levels are higher than the conduction band edge (ECB) of titania, whose commonly accepted values in the DSSC literature are found between -0.2 and $-0.5 \mathrm{~V}$ vs. NHE, that is, between -4.25 and $-3.95 \mathrm{eV}$ vs. vacuum. ${ }^{14}$ The exact position of the ECB of $\mathrm{TiO}_{2}$ is difficult to determine since it can be shifted depending on the acid functionalized dyes and additive molecule's dipole moment. ${ }^{15}$ Due to the presence of the benzoselenadiazole, the LUMO energy level of RKSe approaches that of the conduction band of $\mathrm{TiO}_{2}$ which may limit the efficiency of electron injection into the $\mathrm{TiO}_{2}$ film. For the other dyes the energy difference between the LUMO level and the ECB of the semiconductor is high enough $(0.3 \mathrm{eV})$ to ensure sufficient thermodynamic driving force for the injection of electrons from the excited state of the dyes into the oxide. ${ }^{16}$ As expected, the oxidation potentials of RK1, RK2 and RKSe are quite similar since they possess the same TPA-thiophene unit. The increased electron-donating ability of the substituted or fused TPA units slightly raises the HOMO level of 6RK1, 6ORK1 and RKF. All the
HOMO energy levels of these sensitizers range from -5.37 to

$-5.58 \mathrm{eV}$, indicating that the redox couple $\left(\mathrm{I}^{-} / \mathrm{I}_{3}^{-}\right)$is an appro- priate redox system for the regeneration of the oxidized dyes.

To determine the geometrical configuration and the electro- nic structure of the dyes, molecular orbital calculations were performed by using the hybrid B3LYP functional in combi- nation with the triple zeta basis set. ${ }^{17}$ The good spatial separa- tion of the frontier molecular orbitals was evidenced by DFT calculations (see ESI, $\uparrow$ Fig. S2). Isodensity plots of the HOMO and LUMO energy levels of the dyes show a directional electron distribution, with the delocalization of the HOMOs on the

TPA group and the thiophene and the LUMOs predominantly delocalized on the benzothiadiazole (or benzoselenadiazole) phenylvinylcyanoacetic acid units. This directional electron distribution is consistent with the dissymmetrisation of the core. However, one should note that in the case of RKSe the LUMO energy is preferentially localized over the benzoselenadiazole unit with a small contribution from the anchoring group. Indeed the DFT calculations indicate that the contribution of the benzoselenadiazole to the LUMO of the molecule is $45.5 \%$ whereas the contribution of benzothiadiazole is only $36.7 \%$. This highlights the enhanced electron-withdrawing strength of this unit, explain- ing the shift in absorption that is observed for the ICT band. However the higher localization of the LUMO level mainly on the benzoselenadiazole may be detrimental to the injection process of electrons into the conduction band of the $\mathrm{TiO}_{2}$.

\subsection{Photovoltaic devices with a standard liquid electrolyte}

Fig. 3 shows the action spectra of incident photon-to-current conversion efficiency (IPCE) and the photocurrent-voltage (I-V) plots of DSSCs fabricated with these dyes. The detailed photo- voltaic parameters of the best performing cells, i.e., short circuit current $\left(\mathrm{J}_{\mathrm{sc}}\right)$, open-circuit photovoltage $\left(\mathrm{V}_{\mathrm{oc}}\right)$, fill factor $(\mathrm{FF})$, and the power conversion efficiency $(\mathrm{Z})$, measured under AM 1.5 solar light $\left(1000 \mathrm{~W} \mathrm{~m}^{-2}\right)$ are summarized in Table 2.

The devices were fabricated using screen printed $\mathrm{TiO}_{2}$ films as the working electrode and platinized FTO glass was employed as the counter electrode. The volatile electrolyte used consisted of $0.5 \mathrm{M}$ 1-butyl-3-methylimidazolium iodide (BMII), 0.1 M lithium iodide, $0.05 \mathrm{M}$ iodine and 0.5 $\mathrm{M}$ tert-butyl-pyridine in acetonitrile. In order to demonstrate the reproducibility and the reliability of our devices, the fabrication of the solar cells and the 

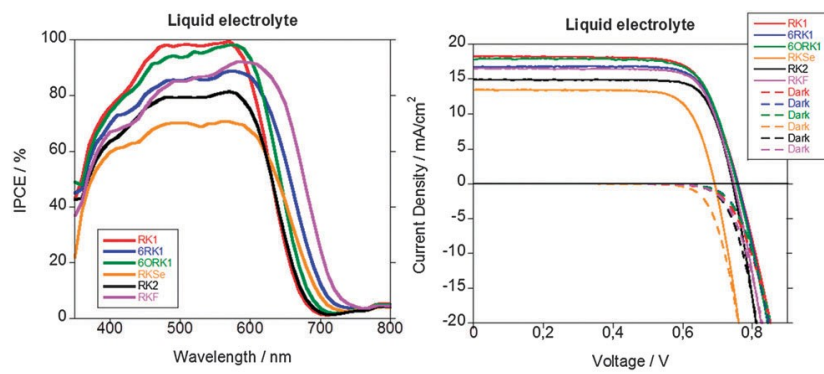

Fig. 3 Left: IPCE curves of liquid electrolyte based DSSCs using optimized parameters, right: $\mathrm{I}-\mathrm{V}$ curves in the dark (dotted lines) and under irradiation (solid lines) of liquid electrolyte based DSSCs using optimized fabrication parameters (aperture area 16 $\mathrm{mm}^{2}$.

measurements of their photovoltaic parameters were carried out independently at ICIQ (aperture area of $0.16 \mathrm{~cm}^{2}$ ) and at Solaronix (aperture area of $0.36 \mathrm{~cm}^{2}$ ). The losses of light reflection and absorption by the conducting glass were not corrected. Many parameters are known to influence the performances of the cells such as the $\mathrm{TiO}_{2}$ thickness.

In this work the best efficiencies were achieved using relatively

high thicknesses varying from 12 to $16 \mathrm{~mm}$ with an additional scattering layer of $4 \mathrm{~mm}$.

For the dyeing of the $\mathrm{TiO}_{2}$ electrodes, several tests using different solvents were carried out. Indeed dyes can exhibit different interactions with solvents which could cause changes of the physical and chemical interactions between the dyes and the surface of the semiconductor. ${ }^{18}$ The dyeing solutions also contain various amounts of chenodeoxycholic acid (CDCA) because this additive is known to diminish the undesirable formation of dye aggregates on the $\mathrm{TiO}_{2}$ surface, ${ }^{19}$ to decrease recombina

tion processes between $\mathrm{TiO}_{2}$ electrons and electrolyte ${ }^{20}$ and to cause positive shifts of the surface potential of the $\mathrm{TiO}_{2}$ leading to an enhancement of $\mathrm{V}_{\mathrm{oc}}{ }^{21}$ We found that the best results are obtained using alcoholic solutions with a dye concentration of

0.2 to $0.5 \mathrm{mM}$ and 2 to $5 \mathrm{mM}$ of CDCA. Clearly, the use of chlorinated solvents such as chloroform decreased the perfor- mances of the cells (see ESI, $\uparrow$ Table S1). The performance of solar cells containing RK1 and various amounts of CDCA (see ESI, $\uparrow$ Table S2) suggests that the co-adsorbent plays a minor role in the dye aggregation in our case, because $\mathrm{J}_{\mathrm{sc}}$ values of the solar cells are not deteriorated even without using CDCA. However we observed that $\mathrm{V}_{\mathrm{oc}}$ increases with increasing concen- tration of CDCA. This suggests that the presence of CDCA leads to a positive shift of the $\mathrm{TiO}_{2}$ vacuum level and thus its $\mathrm{CB}$

edge. $^{21 \mathrm{a}}$ Similar observations, i.e. a minor effect on $\mathrm{J}_{\mathrm{sc}}$ and a strong

improvement in the photovoltage in the presence of CDCA, have also been observed with ruthenium dyes by Neale and co-workers, who emphasized the predominance of shift of $\mathrm{TiO}_{2} \quad \mathrm{CB}$ edge leading to overall higher efficiency. The same mechanism seems to apply to RK dyes.

For optimized devices, RKSe and RK2 show the highest $\mathrm{Z}$ of $8.53 \%$ and $8.71 \%$ respectively, but more interestingly, three dyes revealed $\mathrm{Z}$ over $9.50 \%$ and among them 6 ORK1 overcomes the $10 \%$ efficiency target. These outstanding performances are quite comparable to those of RK1 (our reference dye) and N719 (a ruthenium complex that has been widely used in the scientific

literature as a standard system). ${ }^{5 \mathrm{~d}}$ The combination of a rather

narrow absorption in the visible range with excellent photo- voltaic performances, comparable to among the best for organic dyes, ${ }^{22}$ makes 6RK1, 6ORK1, and RKF very attractive for future developments and applications in solar modules.

It should be underlined that quite high current densities are delivered with these dyes and that the solar cells containing 6ORK1, RKSe and RKF show $\mathrm{J}_{\mathrm{sc}}$ values ranging from $17.80 \mathrm{~mA} \mathrm{~cm} \mathrm{~m}^{-2}$ up to $18.80 \mathrm{~mA} \mathrm{~cm}^{-2}$. For comparison purpose, DSSCs with similar electrode thicknesses were fabricated, i.e. $13+4 \mathrm{~mm}$, masked $0.16 \mathrm{~cm}^{2}$. RK2 and RKSe show the lowest $\mathrm{J}_{\mathrm{sc}}$ in these conditions, whereas 6ORK1 and RK1 show the highest values. These differences cannot be explained by the differences in the optical properties of the dyes because 6ORK1 and RKSe show very similar absorption spectra, and besides, they show almost identical molar extinction coefficients.

The IPCE measurements of the cells confirm that the differences in $\mathrm{J}_{\mathrm{sc}}$ originate in the efficiency of conversion of the photons into electrons. On the other hand, the dyes show quite similar $V_{o c}(0.75$ and $0.76 \mathrm{~V}$ ) except in the case of RKSe which shows a much lower $V_{o c}$ of $0.69 \mathrm{~V}$. It is known that the

Table 2 Photovoltaic parameters of liquid electrolyte based DSSCs using optimized parameters

\begin{tabular}{|c|c|c|c|c|c|c|c|}
\hline & Adsorbing solution & $\mathrm{TiO}_{2}[\mathrm{~mm}]$ & $\operatorname{Mask}\left[\mathrm{mm}^{2}\right]$ & $\mathrm{J}_{\mathrm{sc}}\left[\mathrm{mA} \mathrm{cm}^{-2}\right]$ & $\mathrm{V}_{\mathrm{oc}}[\mathrm{V}]$ & $\mathrm{FF}[\%]$ & $\mathrm{Z}[\%]$ \\
\hline \multirow[t]{2}{*}{ N719 } & $0.5 \mathrm{mM}$ EtOH, $5 \mathrm{mM}$ CDCA & $13+4^{\mathrm{a}}$ & $16^{\mathrm{c}}$ & 17.91 & 0.80 & 71 & 10.19 \\
\hline & $0.5 \mathrm{mM}$ EtOH, $5 \mathrm{mM}$ CDCA & $12.5+3.5^{\mathrm{b}}$ & $36^{\mathrm{d}}$ & 20.21 & 0.72 & 70 & 10.25 \\
\hline \multirow[t]{2}{*}{ RK1 } & 0.5 mM EtOH, 5 mM CDCA & $13+4^{\mathrm{a}}$ & $16^{\mathrm{c}}$ & 18.26 & 0.76 & 74 & 10.20 \\
\hline & $0.2 \mathrm{mM} \mathrm{MeOH}, 2 \mathrm{mM}$ CDCA & $13+3.5^{b}$ & $36^{\mathrm{d}}$ & 19.50 & 0.71 & 72 & 10.00 \\
\hline \multirow[t]{2}{*}{ RK2 } & $0.5 \mathrm{mM}$ EtOH, $5 \mathrm{mM}$ CDCA & $13+4^{a}$ & $16^{\mathrm{c}}$ & 14.92 & 0.75 & 78 & 8.71 \\
\hline & $0.2 \mathrm{mM} \mathrm{MeOH}, 2 \mathrm{mM}$ CDCA & $15+4^{\mathrm{b}}$ & $36^{\mathrm{d}}$ & 15.96 & 0.71 & 73 & 8.22 \\
\hline \multirow[t]{2}{*}{$6 \mathrm{RK} 1$} & $0.5 \mathrm{mM}$ EtOH, 2 mM CDCA & $13+4^{a}$ & $16^{\mathrm{c}}$ & 16.76 & 0.76 & 76 & 9.67 \\
\hline & $0.2 \mathrm{mM}$ ACN-tBuOH, $2 \mathrm{mM}$ CDCA & $12+4^{\mathrm{b}}$ & $36^{\mathrm{d}}$ & 15.96 & 0.74 & 70 & 8.25 \\
\hline \multirow[t]{2}{*}{ 6ORK1 } & $0.2 \mathrm{mM}$ ACN-tBuOH, $2 \mathrm{mM}$ CDCA & $13+4^{a}$ & $16^{\mathrm{c}}$ & 17.81 & 0.76 & 75 & 10.11 \\
\hline & $0.2 \mathrm{mM}$ ACN-tBuOH, $2 \mathrm{mM}$ CDCA & $12+4^{b}$ & $36^{\mathrm{d}}$ & 17.87 & 0.75 & 70 & 9.41 \\
\hline \multirow[t]{2}{*}{ RKSe } & $0.5 \mathrm{mM}$ EtOH, $5 \mathrm{mM}$ CDCA & $13+4^{a}$ & $16^{\mathrm{c}}$ & 13.43 & 0.69 & 77 & 7.14 \\
\hline & $0.2 \mathrm{mM} \mathrm{MeOH}, 2 \mathrm{mM}$ CDCA & $16+4^{b}$ & $36^{\mathrm{d}}$ & 18.37 & 0.67 & 68 & 8.53 \\
\hline \multirow[t]{2}{*}{ RKF } & $0.5 \mathrm{mM}$ EtOH, $5 \mathrm{mM}$ CDCA & $13+4^{a}$ & $16^{\mathrm{c}}$ & 16.55 & 0.75 & 77 & 9.51 \\
\hline & $0.2 \mathrm{mM}$ ACN-tBuOH, $2 \mathrm{mM}$ CDCA & $15+4^{b}$ & $36^{\mathrm{d}}$ & 18.82 & 0.71 & 72 & 9.69 \\
\hline
\end{tabular}

${ }^{\mathrm{a}} \mathrm{TiO}_{2}$ Dyesol (18NR-T 1 18NR-AO). ${ }^{\mathrm{b}} \mathrm{TiO}_{2}$ Solaronix (HT/SP $\left.1 \mathrm{R} / \mathrm{SP}\right) .{ }^{\mathrm{c}}$ Fabrication of the devices and measurements performed at ICIQ.

d Fabrication of the devices and measurements performed at Solaronix. 

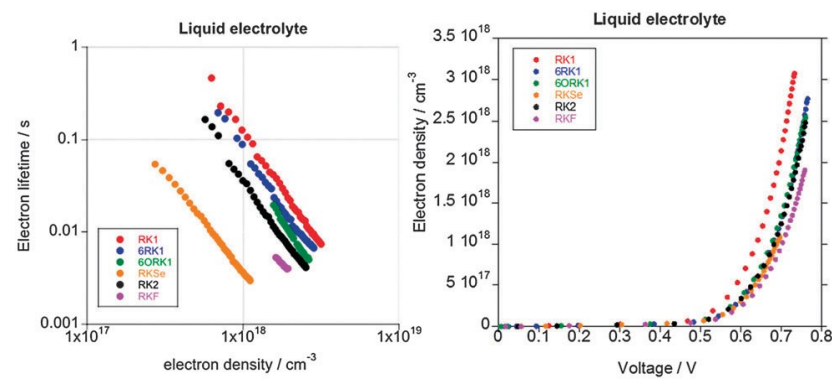

Fig. 4 TPV curves (left) and CE curves (right) of liquid electrolyte based DSSCs using optimized parameters, corresponding to the devices with a $\mathrm{TiO}_{2}$ thickness of 13 $+4 \mathrm{~mm}$.

$\mathrm{V}_{\text {oc }}$ of a DSSC is determined by the difference between the quasiFermi-level of the oxide semiconductor and the redox potential of the electrolyte. The quasi-Fermi-level of the oxide is correlated with its conduction band edge $(\mathrm{Ec})$ and electron density which is itself dependent on the rate of recombination between semiconductor electrons and the electrolyte. As a first approximation to understand the device differences using the different sensitizers, charge extraction (CE) and transient photo- voltage (TPV) measurements were carried out (see Fig. 4). Charge extraction data show similar charge density (defined as the number of charges stored at the solar cell at each different voltage) for all the devices except for the RKSe devices. The TPV experiments reveal that the electron lifetimes are quite similar for all the dyes except for RKSe whose electron lifetime is one order of magnitude shorter compared to the other set of sensi- tizers. It is interesting to perceive that the highest $\mathrm{V}_{\text {oc }}$ of $0.76 \mathrm{~V}$ is achieved with RK1, 6RK1 and 6ORK1, i.e. the dyes with a prolonged lifetime for electrons stored in titania. Based on TPV measurements we can conclude that the charge recombination in RKSe based DSSC is much faster, which a priori explains the much lower $\mathrm{V}_{\mathrm{oc}}$ $(\mathbf{O} 0.70 \mathrm{~V})$ and the lower performance observed under identical illumination conditions.

This peculiar behaviour can be explained by its electronic structure. Indeed, we found by DFT calculations (vide supra and in ESI, $\uparrow$ Fig. S3) that the replacement of the $S$ atom of the benzothiadiazole by a Se induces the spatial localisation of the
LUMO energy level on this unit. This prevents significant localization of the LUMO on the anchoring function and consequently this may hinder good injection of electrons into the oxide explaining the low charge density on these devices. All the other dyes show a directional electron distribution, with the delocalization of the HOMO on the triphenylamine group and the thiophene and a LUMO predominantly delocalized on the BTD-phenylvinylcyanoacetic units. As a consequence they pro- vide a better charge extraction for the devices.

2.4 Photovoltaic devices with an ionic liquid "robust" electrolyte

For real use of DSSCs and future applications in BIPV, in addition to high PCEs, long device lifetimes are required. Highly volatile electrolytes, such as acetonitrile-based ones, must be replaced because they are inappropriate for stability measurements. During the last decade, ionic liquids (IL) have been investigated as alternative solvents in DSSCs due to their numerous appeal- ing properties for DSSC applications. Indeed they can show wide electrochemical windows, a good thermal stability, an extremely low volatility, and a high ionic conductivity combined with the ability to dissolve organic and inorganic compounds. Therefore we have fabricated and characterized solar cells with a solventfree ionic liquid electrolyte with the goal to obtain stable and efficient devices.

Two types of devices were fabricated, using regular meso-

porous $\mathrm{TiO}_{2}$ or a macrochannel $\mathrm{TiO}_{2}$ paste. After careful tuning of the electrodes and optimization of the dyeing conditions, $Z$ values of over $6.1 \%$ were achieved with all the dyes except for RKSe, the better, RKF, reaching circa $7.9 \%$ (Table 3).

For all the dyes combined with ionic liquid electrolytes a significant decrease of $\mathrm{V}_{\mathrm{oc}}$ is observed. The $\mathrm{V}_{\mathrm{oc}}$ of a DSC is determined by the quasi-Fermi-level of the metal oxide semi- conductor, which is correlated with its conduction band edge and the electron density. ${ }^{23 a}$

The electron density is dependent on the rate of recombina- tion between semiconductor electrons and oxidized electrolyte species. Electron lifetimes measured using transient photo- voltage measurements (Fig. 5) are found to be shorter (10 times lower) than for the devices fabricated with a liquid electrolyte.

Table 3 Photovoltaic parameters of ionic liquid electrolyte based DSSCs using optimized parameters

\begin{tabular}{|c|c|c|c|c|c|c|c|}
\hline & Adsorbing solution & $\mathrm{TiO}_{2}[\mathrm{~mm}]$ & $\operatorname{Mask}\left[\mathrm{mm}^{2}\right]$ & $\mathrm{J}_{\mathrm{sc}}\left[\mathrm{mA} \mathrm{cm}^{-2}\right]$ & $\mathrm{V}_{\mathrm{oc}}[\mathrm{V}]$ & $\mathrm{FF}[\%]$ & $\mathrm{Z}[\%]$ \\
\hline \multirow[t]{2}{*}{ RK1 } & $0.5 \mathrm{mM}$ EtOH, 5 mM CDCA & $13+4$ & $16^{\mathrm{b}}$ & 15.77 & 0.70 & 70 & 7.35 \\
\hline & $0.2 \mathrm{mM} \mathrm{MeOH}, 2 \mathrm{mM}$ CDCA & $4+4+3.5^{\mathrm{a}}$ & $36^{\mathrm{c}}$ & 15.40 & 0.67 & 69 & 7.36 \\
\hline \multirow[t]{2}{*}{ RK2 } & 0.5 mM EtOH, 5 mM CDCA & $13+4$ & $16^{\mathrm{b}}$ & 12.04 & 0.68 & 74 & 6.10 \\
\hline & $0.2 \mathrm{mM} \mathrm{MeOH}, 2 \mathrm{mM}$ CDCA & $4+4+3.5^{\mathrm{a}}$ & $36^{\mathrm{c}}$ & 13.49 & 0.63 & 72 & 6.08 \\
\hline \multirow[t]{2}{*}{$6 \mathrm{RK} 1$} & $0.2 \mathrm{mM}$ EtOH, 2 mM CDCA & $13+4$ & $16^{\mathrm{b}}$ & 11.86 & 0.70 & 61 & 5.13 \\
\hline & $0.2 \mathrm{mM}$ ACN-tBuOH, $2 \mathrm{mM}$ CDCA & $4+4+3.5^{\mathrm{a}}$ & $36^{\mathrm{c}}$ & 14.49 & 0.65 & 69 & 6.48 \\
\hline \multirow[t]{2}{*}{ 6ORK1 } & $0.2 \mathrm{mM}$ ACN-tBuOH, 2 mM CDCA & $13+4$ & $16^{\mathrm{b}}$ & 14.18 & 0.69 & 70 & 6.84 \\
\hline & $0.2 \mathrm{mM}$ ETOH$-\mathrm{CHCl}_{3}, 2 \mathrm{mM} \mathrm{CDCA}$ & $4+4+3.5^{\mathrm{a}}$ & $36^{\mathrm{c}}$ & 15.05 & 0.67 & 64 & 6.47 \\
\hline \multirow[t]{2}{*}{ RKSe } & $0.5 \mathrm{mM}$ EtOH, $5 \mathrm{mM}$ CDCA & $13+4$ & $16^{\mathrm{b}}$ & 11.86 & 0.64 & 71 & 5.43 \\
\hline & $0.2 \mathrm{mM}$ ACN-tBuOH, $2 \mathrm{mM} \mathrm{CDCA}$ & $4+4+3.5^{\mathrm{a}}$ & $36^{\mathrm{c}}$ & 12.94 & 0.63 & 71 & 5.75 \\
\hline \multirow[t]{2}{*}{ RKF } & $0.5 \mathrm{mM}$ EtOH, $5 \mathrm{mM}$ CDCA & $13+4$ & $16^{\mathrm{b}}$ & 15.24 & 0.69 & 69 & 7.27 \\
\hline & $0.2 \mathrm{mM} \mathrm{MeOH}, 2 \mathrm{mM}$ CDCA & $4+4+3.5^{\mathrm{a}}$ & $36^{\mathrm{c}}$ & 17.50 & 0.67 & 67 & 7.87 \\
\hline
\end{tabular}

${ }^{\text {a }} \mathrm{TiO}_{2}$ macrochannel Solaronix $(\mathrm{HT} / \mathrm{SP} 1 \mathrm{MC} / \mathrm{SP} 1 \mathrm{R} / \mathrm{SP}){ }^{\mathrm{b}}$ Fabrication and measurements performed at ICIQ. ${ }^{\mathrm{c}}$ Fabrication and measurements performed at Solaronix. 

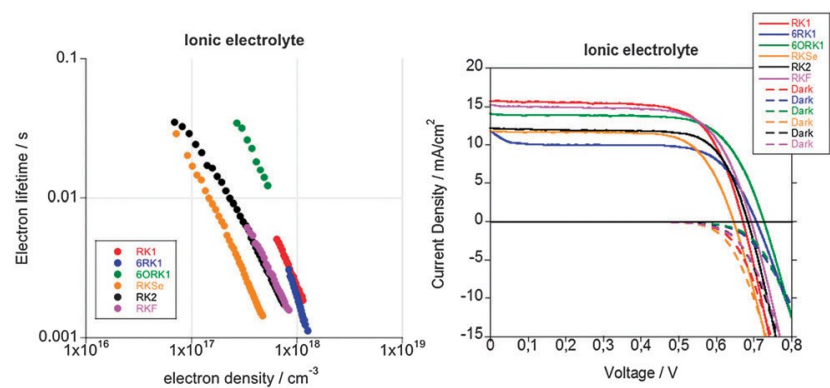

Fig. 5 TPV curves (left) and I-V curves (right) of ionic electrolyte based DSSCs using optimized parameters (electrode thickness $13+4 \mathrm{~mm}$, aperture area 0.16 $\mathrm{cm}^{2}$.

This behaviour has systematically been reported for these electrolytes. ${ }^{23 \mathrm{~b}}$ Therefore, the combined effect of the lower lying $\mathrm{TiO}_{2}$ conduction band and shorter electron lifetime explains the general trend of lower $\mathrm{V}_{\mathrm{oc}}$ for these devices compared to DSSCs with the acetonitrile electrolyte.

With $8 \mathrm{~mm}$ thick $\mathrm{TiO}_{2}$ films coated with a $3.5 \mathrm{~mm}$ thick reflecting layer, RKF containing devices showed an impressive $\mathrm{J}_{\mathrm{sc}}$ of 17.50 $\mathrm{mA} \mathrm{cm}{ }^{-2}$, a $\mathrm{V}_{\text {oc }}$ of $0.67 \mathrm{~V}$, and a FF of $67 \%$ yielding a $\mathrm{Z}$ of $7.87 \%$ at $1 \mathrm{Sun}$. This performance is better than that of RK1 (our reference dye) and is considerably better than most of the performances using ionic liquid based electrolytes employing

$\left(\mathrm{I}^{-} / \mathrm{I}_{3}{ }^{-}\right)$as a redox shuttle that are reported for organic sensitizers. ${ }^{24}$ This performance approaches the record efficiencies of the best ruthenium-based dyes under the AM $1.5 \mathrm{G}$ full sunlight. ${ }^{25}$

\subsection{Stability tests and solar module application}

For any emerging photovoltaic technology, it is very critical to fulfil a long-term stability criterion. Besides it is important to assess its potential for large scale applications. ${ }^{26}$ However, for probing the stability of new systems it is not practical to make a large solar panel and perform outdoor evaluation over long

periods. Hence, we submitted our laboratory cells covered with a UV absorbing polymer film to a $3000 \mathrm{~h}$ accelerated testing at

$65 \mathrm{1C}$, in a solar simulator with a light intensity of $1000 \mathrm{~W} \mathrm{~m}^{-2}$.

In Fig. 6, the evolution of the PCE measured at different time intervals under the irradiance of AM $1.5 \mathrm{G}$ is shown. After light

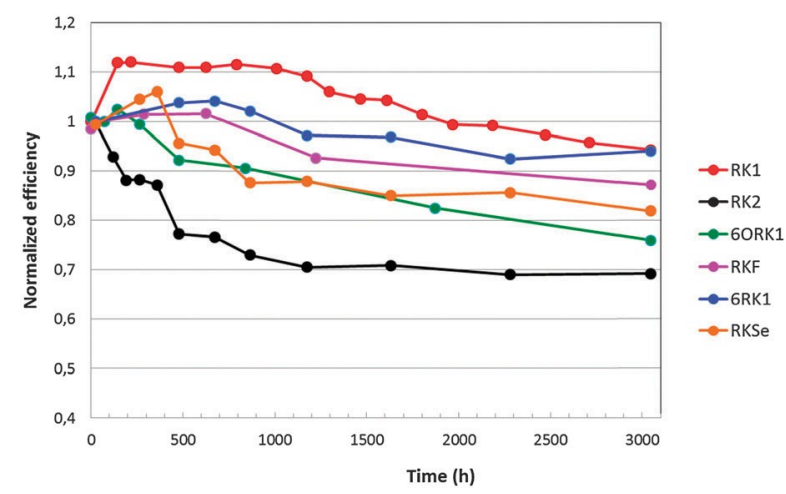

Fig. 6 Variation of the PCE of the solar cells measured under the irradiance of AM $1.5 \mathrm{G}$ sunlight during successive full-sun visible-light soaking (1 Sun $1000 \mathrm{~W} \mathrm{~m}^{-2}$ ) at $651 \mathrm{C}$. soaking, the photocurrent and power conversion efficiency of some of the solar cells increases

This behaviour is related to the improved penetration of the ionic liquid electrolyte through the mesoporous film and the "activation" of the entire electrode in depth. ${ }^{27}$ With the exception of 6ORK1- and RK2-based devices that showed a loss of $30 \%$ and $25 \%$, respectively, of their initial effciency after $3000 \mathrm{~h}$, all the other solar cells reveal rather stable performances. RK1 and 6RK1 appear as the most robust dyes since they maintain

$95 \%$ of their initial performances in the same time interval. It should be noticed that RK1 devices can stably perform for more than 9000 hours under these harsh conditions with a loss of only

$30 \%$ of the initial efficiency. From the literature, this stability performance is the best ever achieved for an organic sensitizer (see ESI, $\uparrow$ Fig. S4).

Owing to its high effciency and its outstanding stability, we identified RK1 as a promising organic dye for the fabrication of a prototype of large area $\left(4500 \mathrm{~cm}^{2}\right)$ photovoltaic modules (Fig. 7).

On FTO coated glass $(35 \mathrm{~cm} \times 50 \mathrm{~cm}), 13$ single cells were interconnected in series using a W-type design with an overall active area of $1400 \mathrm{~cm}^{2}$ representing $80 \%$ of the total area (see Fig. 7). The solution processing steps (i.e. printing of the electrodes and dyeing procedure) were identical to those when the small area cells are fabricated.

For the fabrication of the

module an ionic liquid electrolyte was used and introduced by

capillarity. In order to achieve a good semi-transparency in the visible and to facilitate the penetration of the electrolyte, the thickness of the titania electrode was kept at $2 \mathrm{~mm}$ without any scattering layer. The completed solar cells show an aesthetic red-orange colour with a transmittance over $50 \%$ between

$620 \mathrm{~nm}$ and $1000 \mathrm{~nm}$ (see ESI, $\uparrow$ Fig. S5).

The first prototype of this large-area module showed a current, $\mathrm{I}_{\mathrm{sc}}$, of $692 \mathrm{~mA}$, a $\mathrm{V}_{\mathrm{oc}}$ of $8 \mathrm{~V}$, and a FF of $26.5 \%$ leading to a power output of $10.5 \mathrm{~W} \mathrm{~m}^{-2}$ when tested under $1 \mathrm{Sun}$

irradiation. When tested under 0.3 Sun the power output of the panel still reached $7.3 \mathrm{~W} \mathrm{~m}^{-2}$. The low $\mathrm{FF}$ of this preliminary prototype can be explained by the higher series resistance in this device configuration, whereas the deteriorated current

density compared to our best solar cells is attributed to the extremely thin titania layer that was employed. Further developments are in progress to boost the performances of the modules.

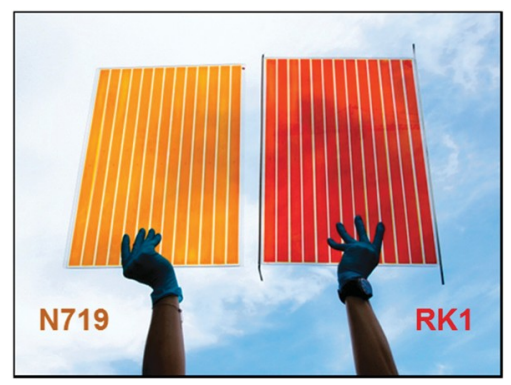

Fig. 7 Picture of the large area solar panels fabricated at Solaronix. 


\section{Conclusions}

In summary, we have designed, synthesised and characterized a series of structurally simple dissymmetric organic dyes for DSSCs. Four of the new dyes have demonstrated power conver- sion efficiencies over $9.5 \%$ and two of them have exceeded $10 \%$ effciency when combined with an iodinebased electrolyte. The replacement of the volatile electrolyte by an ionic liquid yielded solar cells with power conversion efficiencies up to $7.9 \%$ show- ing very promising stability of the performances under accelerated ageing conditions. Finally, the most robust organic dye, RK1, has been successfully incorporated in a large area solar panel $\left(1750 \mathrm{~cm}^{2}\right)$ exhibiting high transparency in the visible range with a power output of $10.5 \mathrm{~W} \mathrm{~m}^{-2}$. This work highlights the potential of metal-free organic dyes for future applications in buildingintegrated photovoltaics.

\section{Acknowledgements}

The authors acknowledge the European Union Research Executive Agency for funding through the Adios-Ru research project. This project is funded by the European Union Research Executive Agency (contract 315131) on the Research for SMEs programme. E.P. acknowledges ICIQ and ICREA for financial support. E.P. thanks the MICINN for projects CTQ2013-47183-R and the Severo Ochoa Excellence Accreditation 2014.2018 (SEV-2013-0319).

\section{Notes and references}

1 (a) M. Grätzel, Nature, 2001, 414, 338; (b) B. O’Regan and M. Grätzel, Nature, 1991, 353, 737; (c) T. W. Hamann and J. W. Ondersma, Energy Environ. Sci., 2011, 4, 370; (d) N. Memarian, I. Concina, A. Braga, S. M. Rozati, A. Vomiero and G. Sberveglieri, Angew. Chem., Int. Ed.,

2011, 50, 12321; (e) D. Hwang, J.-S. Jin, H. Lee, H.-J. Kim, H. Chung, D.-Y. Kim, S.-Y. Jang and D. Kim, Sci. Rep., 2014,

4, 7353; (f) S.-H. Choi, D. Hwang, D.-Y. Kim, Y. Kervella, P. Maldivi, S.-Y. Jang, R. Demadrille and I.-D. Kim, Adv. Funct. Mater., 2013, 23, 3146.

2 S. Ahmad, E. Guillen, L. Kavan, M. Grätzel and M. K. Nazeeruddin, Energy Environ. Sci., 2013, 6, 3439.

3 W. M. Campbell, K. W. Jolley, P. Wagner, K. Wagner, P. J. Walsh, K. C. Gordon, L. Schmidt-Mende, M. K. Nazeeruddin, Q. Wang, M. Grätzel and D. L. Officer, J. Phys. Chem. C, 2007, 111, 11760.

4 (a) A. Yella, H.-W. Lee, H. N. Tsao, C. Yi, A. K. Chandiran, M. K. Nazeeruddin, E. W.-G. Diau, C.-Y. Yeh, S. M. Zakeeruddin and M. Grätzel, Science, 2011, 334, 629; (b) S. Mathew, A. Yella, P. Gao, R. Humphry-Baker, B. F. E. Curchod, N. Ashari-Astani, I. Tavernelli, U. Rothlisberger, M. K. Nazeeruddin and M. Grätzel, Nat. Chem., 2014, 6, 242; (c) A. Yella, C.-L. Mai, S. M. Zakeeruddin, S.-N. Chang, C.-H. Hsieh, C.-Y. Yeh and M. Grätzel, Angew. Chem., Int. Ed.,

2014, 53, 2973.

5 (a) A. Dessi, M. Calamante, A. Mordini, M. Peruzzini, A. Sinicropi, R. Basosi, F. Fabrizi de Biani, M. Taddei,

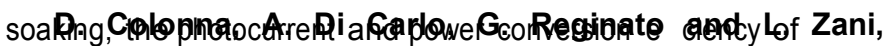
Chem.Commun., 2014, 50, 13952; (b) G. Zhang, H. Bala, Y. Cheng, D. Shi, X. Lv, Q. Yu and P. Wang, Chem. Commun., 2009,

2198; (c) W. Zeng, Y. Cao, Y. Bai, Y. Wang, Y. Shi, M. Zhang, F. Wang, C. Pan and P. Wang, Chem. Mater., 2010, 22, 1915; (d) S. Ito, H. Miura, S. Uchida, M. Takata, K. Sumioka, P. Liska, P. Comte, P. Pechy and M. Grätzel, Chem. Commun.,

2008, 5194; (e) D. Joly, L. Pelleja, S. Narbey, F. Oswald, J. Chiron, J. N. Clifford, E. Palomares and R. Demadrille, Sci. Rep., 2014, 4, 4033; ( f ) Z. Yao, H. Wu, Y. Ren, Y. Guo and P. Wang, Energy Environ. Sci., 2015, 8, 1438.

6 Z. Yu, N. Vlachopoulos, M. Gorlov and L. Kloo, Dalton Trans., 2011, 40, 10289.

7 (a) S. K. Pathak, A. Abate, T. Leijtens, D. J. Hollman, J. Teuscher, L. Pazos, P. Docampo, U. Steiner and H. J. Snaith, Adv. Energy Mater., 2014, 1301667; (b) M. K. Kashif, M. Nippe, N. W. Duffy, C. M. Forsyth, C. J. Chang, J. R. Long, L. Spiccia and U. Bach, Angew. Chem., Int. Ed., 2013, 52, 5527.

8 Z. Ning and H. Tian, Chem. Commun., 2009, 5483.

9 (a) Z. Ning, Y. Fu and H. Tian, Energy Environ. Sci., 2010, 3, 1170; (b) M. Xu, R. Li, N. Pootrakulchote, D. Shi, J. Guo, Z. Yi, S. M. Zakeeruddin, M. Grätzel and P. Wang, J. Phys. Chem. C, 2008, 112, 19770.

10 (a) Y. Ooyama and Y. Harima, Eur. J. Org. Chem., 2009, 2903; (b) Y. Ooyama and Y. Harima, ChemPhysChem, 2012, 13, 4032.

11 Q. Feng, W. Zhang, G. Zhou and Z.-S. Wang, Chem. - Asian J., 2013, 8, 168.

12 M. Velusamy, K. R. J. Thomas, J. T. Lin, Y.-C. Hsu and K.-C. Ho, Org. Lett., 2005, 7, 1899.

13 (a) K. Lim, C. Kim, J. Song, T. Yu, W. Lim, K. Song, P. Wang, N. $\mathrm{Zu}$ and J. Ko, J. Phys. Chem. C, 2011, 115, 22640; (b) H. Choi, J. K. Lee, K. H. Song, K. Song, S. O. Kang and J. Ko, Tetrahedron, 2007, 63, 3115.

14 (a) M. Grätzel, Nature, 2001, 414, 338-344; (b) I. Chung, B. Lee, J. He, R. P. H. Chang and M. G. Kanatzidis, Nature, 2012, 485, 486-489.

15 F. Ambrosio, N. Martsinovich and A. Troisi, J. Phys. Chem. C, 2012, 116, 2622-2629.

16 (a) A. Hagfeldt and M. Grätzel, Chem. Rev., 1995, 95, 49; (b) P. Wang, S. M. Zakeeruddin, J.-E. Moser and M. Grätzel, J. Phys. Chem. B, 2003, 107, 13280.

17 (a) A. D. Becke, J. Chem. Phys., 1993, 98, 5648; (b) SCM, ADF2010, Vrije Universiteit, Amsterdam, The Netherlands, http://www.scm.com. G. te Velde, F. M. Bickelhaupt, E. J. Baerends, C. F. Guerra, S. J. A. Van Gisbergen, J. G. Snijders and T. Ziegler, J. Comput. Chem., 2001, 22, 931-967.

18 (a) N. Robertson, Angew. Chem., Int. Ed., 2006, 45, 2338;

(b) C. Sakong, S. H. Kim, S. B. Yuk, J. W. Namgoong, S. W. Park, M. J. Ko, D. H. Kim, K. S. Hong and J. P. Kim, Chem. Asian J., 2012, 7(60), 1817; (c) H. Ozawa, M. Awa, J. Ono and H. Arakawa, Chem. - Asian J., 2012, 7, 156; (d) W. Ying, F. Guo, J. Li, Q. Zhang, W. Wu, H. Tian and J. Hua, ACS Appl. Mater. Interfaces, 2012, 4, 4215; (e) S. Cai, X. Hu, Z. Zhang, J. Su, X. Li, A. Islam, L. Han and H. Tian, J. Mater. Chem. A, 2013, 1, 4763. 
T. Geiger, F. Nüesch, M. Grätzel and M. K. Nazeeruddin, Nanotechnology, 2008, 19, 424005.

20 A. C. Khazraji, S. Hotchandani, S. Das and P. V. Kamat, J. Phys. Chem. B, 1999, 103, 4693.

21 (a) S. Sakaguchi, S. S. Pandey, K. Okada, Y. Yamaguchi and S. Hayase, Appl. Phys. Express, 2008, 1, 105001; (b) N. R. Neale, N. Kopidakis, J. van de Lagemaat, M. Grätzel and A. J. Frank, J. Phys. Chem. B, 2005, 109, 23183.

22 M. Liang and J. Chen, Chem. Soc. Rev., 2013, 42, 3453.

23 (a) J. Idigoras, R. Tena-Zaerab and J. A. Anta, Phys. Chem. Chem. Phys., 2014, 16, 21513; (b) F. Fabregat-Santiago, J. Bisquert, E. Palomares, L. Otero, D. B. Kuang, S. M. Zakeeruddin and M. Grätzel, J. Phys. Chem. C, 2007, 111, 6550-6560.
Int. Ed., 2009, 48, 2474.

25 (a) S. M. Zakeeruddin and M. Grätzel, Adv. Funct. Mater., 2009, 19, 2187; (b) M. Gorlov and L. Kloo, Dalton Trans., 2008, 2655; (c) D. Shi, N. Pootrakulchote, R. Z. Li, J. Guo, Y. Wang, S. M. Zakeeruddin, M. Gratzel and P. Wang, J. Phys. Chem. C, 2008, 112, 17046.

26 (a) A. Fakharuddin, R. Jose, T. M. Brown, F. FabregatSantiago and J. Bisquert, Energy Environ. Sci., 2014, 7, 3952; (b) A. Hinsch, H. Brandt, W. Veurman, S. Hemming, M. Nittel, U. Würfel, P. Putyra, C. Lang-Koetz, M. Stabe, S. Beucker and K. Fichter, Sol. Energy Mater. Sol. Cells, 2009, 93, 820 .

27 Z. Zhang, S. Ito, J.-E. Moser, S. M. Zakeeruddin and M. Grätzel, ChemPhysChem, 2009, 10, 1834. 